\section{Emphysematous Pyelonephritis: Case Series and Review of the Literature}

\section{Abstract}

Introduction: Emphysematous pyelonephritis (EPN) is a rare gas-forming infection of renal parenchyma and excretory system and surrounding renal areas. It has a low incidence but high mortality (15-20\%).

Objectives: Our goal is to report our series of EPN and review the literature about this entity to improve its management.

Materials and Methods: We analyze three EPN cases, in our Centre from 2017 to 2019, two women and one man between 45-84-years-old. Common symptoms were pain and fever with fatal evolution to septic shock in one of them. Medical management was adopted in all of them. Percutaneous nephrostomy was needed in two cases to complete treatment. And one case of dry type EPN required an urgent nephrectomy. Escherichia coli was isolated in all cases. Mortality rate reached $33.3 \%$.

Discussion and Conclusion: EPN is a rare and severe necrotizing infection of renal parenchyma and its surrounding areas. It appears most commonly in females (6: $1)$. Diabetes mellitus is the main risk factor and urinary obstruction occurs in 25$40 \%$. Escherichia coli is isolated in $70 \%$. There are many classifications to establish the best treatment according to stage. The most complete is Huang and Tseng classification (2000), based on CT radiological findings. Systolic pressure $<90$ $\mathrm{mmHg}$, thrombocytopenia, bilateral EPN are associated with poor prognosis. Early medical treatment is essential. The most accepted management consist of support measures with percutaneous nephrostomy. In not-responding patients and those with bad prognosis, urgent nephrectomy can be necessary.

Keywords: Emphysematous pyelonephritis; Percutaneous drainage; Conservative management
López MLP*

Department of Urology, "Virgendel Rocío" Hospital \& University, Spain

*Corresponding author:

María Loreto Parra López

\section{loreto.parra.lopez@gmail.com}

Médico-interno Residente, Department of Urology, "Virgendel Rocío" Hospital \& University, Spain.

Tel: +3474582074

Citation: López MLP (2020) Emphysematous Pyelonephritis: Case Series and Review of the Literature. Insights Biomed Vol.5 No.2:4

\section{Introduction}

Pyelonephritis emphysematous (PNE) is a necrotizing infection characterized by gas within renal parenchyma, urinary system and perinephric tissues [1,2]. This entity has a low incidence but high mortality even more than $15-20 \% 3]$. The objective is to show the series in our Centre from 2017 to 2019 and review the literature about PNE to improve and homogenize its management.

\section{Case Number 1}

Medical history: A 45-years-old woman who suffers from hypertension and non-controlled Type II Diabetes Mellitus history.

Symptoms: She presented a severe constitutional syndrome and pain on left renal fossa. She also developed high fevers at home $(40 \mathrm{C})$.

Examination: General examination showed bad general condition, with neurologic impairment (Glasgow Coma Scale (GCS 8), hemodynamic instability with blood pressure (BP) of $87 / 51 \mathrm{mmHg}$, tachycardia (110 bpm), tachypnea (20 bpm) and hypothermia (32.8 )

Initial complementary tests: Urine sample showed ketones and leucocyturia. Bloodcount obtained leucocytosis (40.000 $\mathrm{cel} / \mathrm{mm}^{3}$ ), neutrophilia $80 \%$ and normal platelets. Biochemistry identified high creatinine levels $(2.47 \mathrm{mg} / \mathrm{dl})$, hypokalaemia (3 mEq/L) and glycaemia $600 \mathrm{mg} / \mathrm{dl}$, severe metabolic acidosis 
(pH 6.9 and bicarbonate, $10.1 \mathrm{mEq} / \mathrm{L}$, Lactic Acid $6 \mathrm{mmol} / \mathrm{L}$ ) and high acute phase reactants levels (C reactive protein $420 \mathrm{mg} / \mathrm{l}$ ).

Initial clinical judgment: The initial diagnosis was a diabetic ketoacidosis event according to her medical history.

Treatment: Firstly, we combined fluids: 3500 cc-physiological saline+ 500 cc-volume expansor such as Gelofusinewith intravenous insulin therapy (24UI), bicarbonate 1/6M (250 cc) and potassium chloride $(20 \mathrm{mEq} / \mathrm{l})$ and empirical antibiotic therapy (Ciprofloxacin $400 \mathrm{mg}$ IV).

Evolution: The evolution was torpid towards septic shock with apnoea pauses and pulseless electrical activity with need for orotracheal intubation and advanced cardio-pulmonary reanimation manoeuvres. Once she was stabilized in the Intensive Care Unit (ICU), several imaging techniques were performed:

Abdominal US: A slight amount of free peritoneal liquid and inability to visualize the left kidney due to gas interposition. Taking into account of these findings we decided to extend the image study with a CT.

Contrast-enhanced abdominal CT: A CT showed a severe left emphysematous pyelonephritis with venous thrombosis and a moderate amount of free peritoneal liquid (Figures 1 and 2).

Diagnosis: Emphysematous pyelonephritis grade IIla according to radiological classification because there was perinephric gas.

Definitive management: In the absence of urinary obstruction that had permitted percutaneous access, clinical evolution and fatal prognostic factors, urgent open left nephrectomy was decided.

Evolution: At ICU, patient remained on mechanical ventilation in a controlled volume mode, $40 \% \mathrm{FiO}_{2}, 16 \mathrm{bpm}$ and $100 \%$ oxygen saturation. She stayed under sedation with morphic chloride 0.5 $\mathrm{mg} / \mathrm{h}$. The antibiotic was changed to Meropenem $1 \mathrm{~g} / 8 \mathrm{~h} \mathrm{IV.}$

Patient needed initially, Noradrenaline (NA) $0.55 \mathrm{mcg} / \mathrm{kg} / \mathrm{min}$ to maintain blood pressure above $80 / 50 \mathrm{mmHg}$ and also required

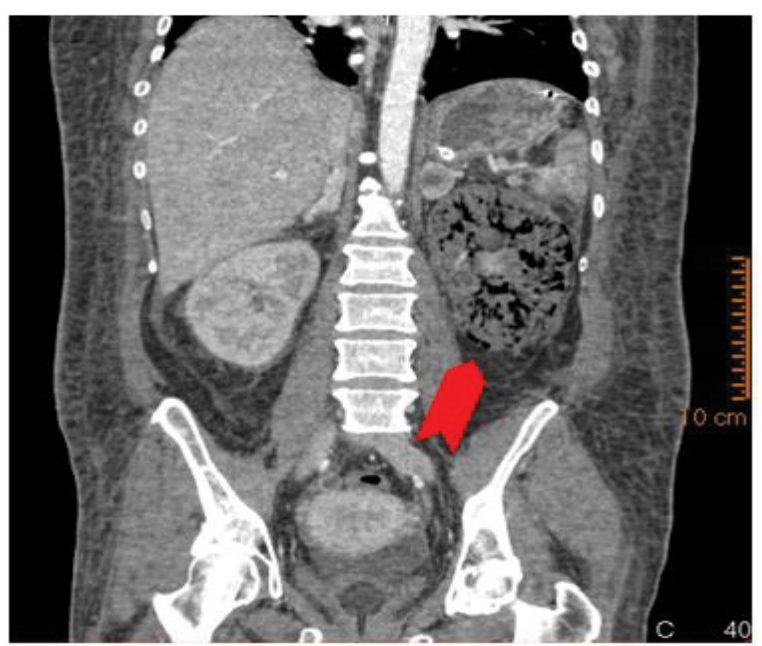

Figure 1 Emphysematous pyelonephritis grade Illa with gas in urinary system, parenchyma and perinephric gas.

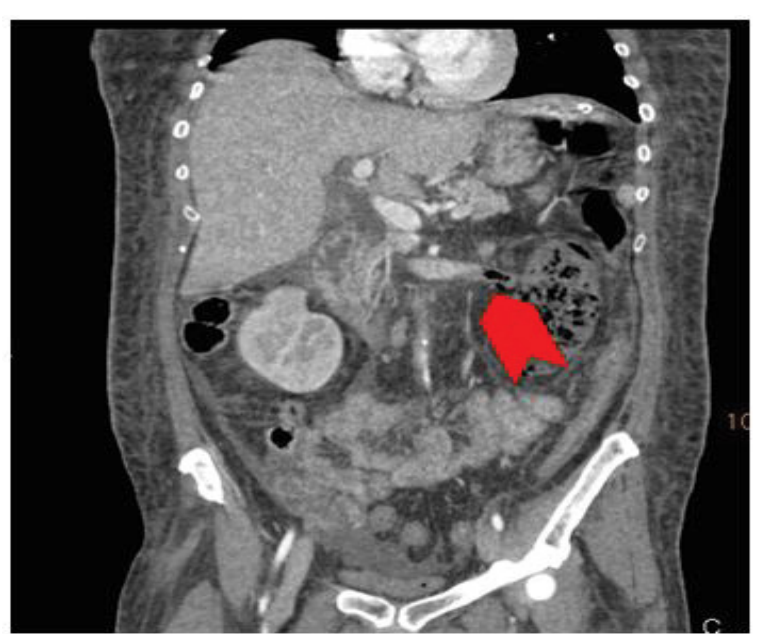

Figure 2 Gas and venous thrombosis.

continuous venous hemofiltration at $250 \mathrm{ml} / \mathrm{min}$ with volume replacement of $2500 \mathrm{ml} / \mathrm{h}$ and extraction of $500 \mathrm{ml} / \mathrm{h}$ associated with treatment with heparin $5 \mathrm{Ul} / \mathrm{kg} / \mathrm{h}$.

After surgery, hemodynamic and renal function improvement was achieved although neurological prognosis (GSC 4; E1V1M2) was poor with hypoxic-ischemic encephalopathy and absence of cortical response.

A decrease of NA doses was possible from 0.55 to $0,05 \mathrm{mcg} / \mathrm{kg} /$ min in next 24 hours.

Blood count obtained a significant improvement in leucocytosis $\left(40.000 \mathrm{cel} / \mathrm{mm}^{3} \rightarrow 14.000 \mathrm{cel} / \mathrm{mm}^{3}\right)$, neutrophilia $(80 \% \rightarrow 74 \%)$ and thrombocytosis $\left(541.000 \mathrm{cel} / \mathrm{mm}^{3}\right)$. Biochemistry identified a significant improvement in creatinine levels $(2.47 \mathrm{mg} / \mathrm{dl} \rightarrow 1,32$ $\mathrm{mg} / \mathrm{dl}$ ) and ions (K $3.5 \mathrm{mEq} / \mathrm{l})$.

A neuroelectrophysiological study was performed showing isoelectric tracing without cortical reactivity to nociceptive stimuli, which in the absence of sedative medication is concordant with absence of brain activity and the neuroelectrophysiological study, a study of somesthetic evoked potentials was carried out with no corticalresponses anddiencephalic injury. So, unfavorable outcomes were expected. Unfortunately, patient died at the thirteenth day in the ICU.

\section{Case Number 2}

Medical history: A 69-year-old man diagnosed and treated of hypertension, hemispheric stroke and smoking habits. He underwent left hernioplasty 2 years ago.

Symptoms: He was admitted on Neurology ward on suspicion of right ischemic stroke with left hemiparesis and dysarthria with neurologic impairment (GCS 10).

He suffered from abdominal pain since two days. Pain was located on left renal fossa and irradiating to the left inguinal region. He also had diarrhoea and maintained febricula with evening high fevers as high as 38.5 으.

Examination: He presented a poor general condition, neurologic 
impairment (Glasgow 12), eupneic, hemodynamically stable with BP $130 / 80 \mathrm{mmHg}$, tachycardia (120 bpm). The temperature was 37.7 으.

Initial complementary tests: Urine Sample showed leucocituria and microscopic haematuria. Blood count obtained leucocytosis $\left(41,000 \mathrm{cel} / \mathrm{mm}^{3}\right)$ and neutrophilia $89 \%$. Biochemistry showed high levels of Creatinine $(2.7 \mathrm{mg} / \mathrm{dl})$ and high acute phase reactants levels (C reactive protein $375 \mathrm{mg} / \mathrm{l}$ ). No significant alterations in venous gasometry were found.

In Neurology ward a Head CT had been permormed and the results were inconclusive with hypodense areas in right basal ganglia suggestive of lacunar infarcts versus dilated VirchowRobin spaces. Initial clinical judgment is right hemispheric stroke. Fever is without diagnosed focus.

Evolution: Persistence of fever and elevation of reactants of acute phase that guide an infectious context. Because of that, we performed an abdominal ultrasound and any pathological findings were founded.

Finally, the abdominal CT revealed a left pyeloureteritis with gas in the urinary system and slight ureterohydronephrosis secondary to millimetre lithiasis $(5 \mathrm{~mm})$ in the left distal ureter (Figures 3 and 4).

Diagnosis: Emphysematous pyelonephritis grade I according to radiological classification so there was gas only in the excretory system.

Definitive management: fluid therapy with 1500 cc-physiological saline, empirical antibiotic therapy with intravenous Piperacillin/ Tazobactam $4 \mathrm{~g} / 0.5 \mathrm{~g}$ three times a day and urgent urinary diversion through ultrasound (US)-guided left percutaneous

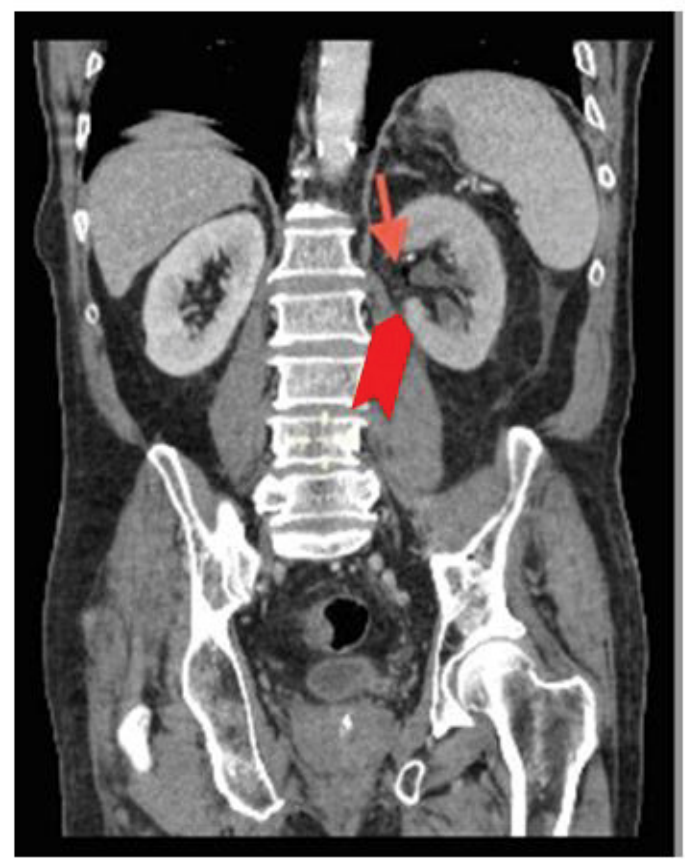

Figure 3 PNE grade I with gas only in the excretory system

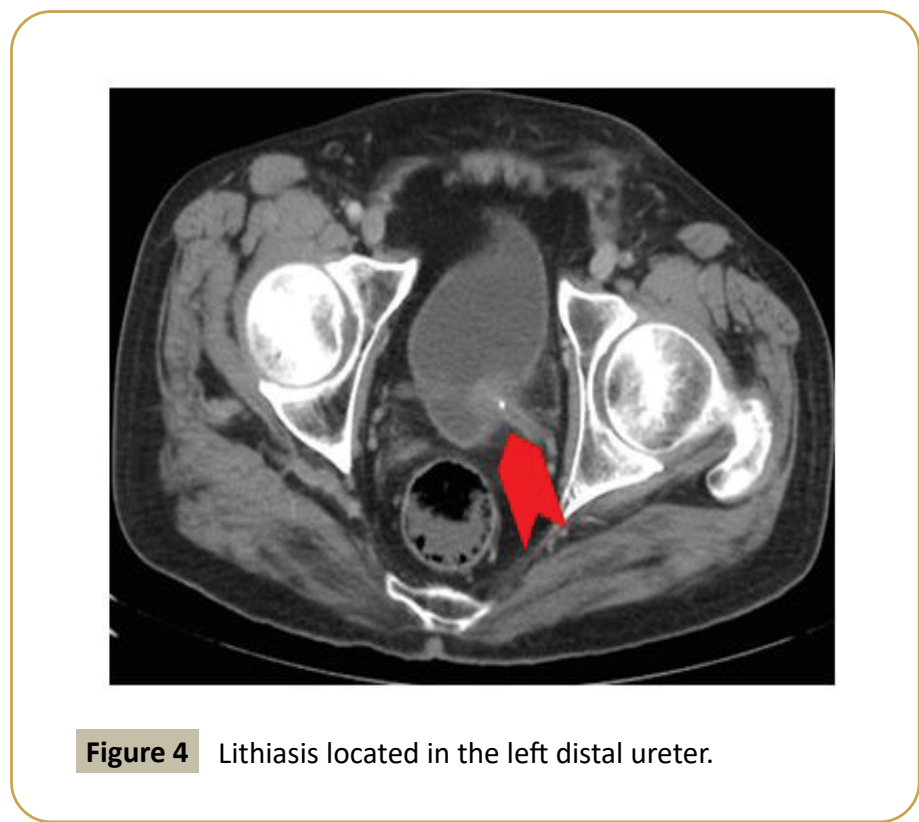

nephrostomy $8 \mathrm{Fr} \times 26 \mathrm{~cm}$. Escherichia coli was the isolated agent in blood and urine samples.

Evolution: We modified the antbiotic therapy to AmoxicilinClavulanic Acid 1g/8h, 3 days after, when the urine culture results showed a mutisensible Escherichia coli. The clinical evolution was satisfactory without fever after urinary derivation and antibiotics tehrapy. We kept the intravenous antibiotic for 2 days longer until the blood test normalized (leucocytosis, CRP and Creatinine). Patient was discharged 5 days later with the same oral antibiotic treatment during 2 weeks. After acute episode, patient was prepared to left semi-rigid ureteroscopy to remove the distal ureter lithiasis and the nephrostomy tube was removed 24 hours after surgery.

\section{Case Number 3}

Medical history: A 84-year-old woman who suffered from hypertension, dyslipidaemia, atrial fibrillation, hypertensive heart disease and severe aortic stenosis.

Symptoms: She presented haematuria associated with abdominal pain on the right renal fossa. She also started with high fever up to $38^{\circ} \mathrm{C}$ two days after the pain appeared.

Examination: Bad general condition with impaired neurological status (Glasgow 10). Hemodynamically stable (BP $120 / 70 \mathrm{mmHg}$, FC 90 lpm). Tachypnea (28 bpm). Temperature was 37으.

Initial complementary tests: Elemental urine showed leucocyturia and microscopic haematuria. Blood count obtained neutrophilia (87\%) without leucocytosis $\left(11.000 \mathrm{cell} / \mathrm{mm}^{3}\right)$ and normal platelets. Biochemistry showed levels slightly high of creatinine $(\mathrm{Cr} 1.5 \mathrm{mg} / \mathrm{dl})$ and high acute phase reactants levels (C reactive protein $280 \mathrm{mg} / \mathrm{l}$ ) with metabolic acidosis $(\mathrm{pH} 7.2$, bicarbonate, $18.1 \mathrm{mEq} / \mathrm{L}$ and Lactic Acid $4 \mathrm{mmol} / \mathrm{L}$ ) and high acute phase reactants levels (C reactive protein $420 \mathrm{mg} / \mathrm{l}$ ).

Initial clinical judgment: Right acute pyelonephritis.

Evolution: The evolution developed towards septic shock 
that required Intensive Cares. An abdominal ultrasound was performance, which described emphysematous pyelitis with pyonephrosis and gas in the right renal pelvis with moderate hydronephrosis.

Diagnosis: Emphysematous pyelonephritis grade I.

Definitive management: She was managed in the ICU with supportive measures and empirical intravenous antibiotic was started with Ceftriaxone $2 \mathrm{~g}$ (charge dose) and Ceftriaxone $1 \mathrm{~g} / 24$ $\mathrm{h}$ as well as urgent urinary diversion through right US-guided percutaneous nephrostomy $8 \mathrm{Fr} \times 26 \mathrm{~cm}$. Escherichia coli was the isolated agent in blood and urine samples.

Patient needed initially, Noradrenaline (NA) $0.1 \mathrm{mcg} / \mathrm{kg} / \mathrm{min}$ to maintain blood pressure above $90 / 60 \mathrm{mmHg}$ and fluids $2500 \mathrm{cc}-$ physiological saline.

After antibiotics therapy and urinary derivation, a progressive decrease of NA doses was possible in $24 \mathrm{hrs}$. Blood count obtained a significant improvement in neutrophilia $(87 \% \rightarrow 75 \%)$ and Biochemistry identified a normalization in creatinine levels $(1.50 \mathrm{mg} / \mathrm{dl} \rightarrow 0.90 \mathrm{mg} / \mathrm{dl})$ and CRP values $(420 \mathrm{mg} / \mathrm{l} 320 \mathrm{mg} / \mathrm{l}$ and also venous gasometry improvement was detected $(\mathrm{pH} 7.33$, bicarbonate, $20 \mathrm{mEq} / \mathrm{L}$ and Lactic Acid $1 \mathrm{mmol} / \mathrm{l})$.

Evolution: Patients was stabilized for 48 hours in the ICU with excellent evolution.

A control CT scan was performed, showing only signs of right pyelitis. No obstructive causes were identified. After clinical and analytical normalization, discharge was decided on the seventh day. We modified the antbiotic therapy to Amoxicilin Clavulanic Acid $1 \mathrm{~g} / 8 \mathrm{~h}, 3$ days after, when the urine culture results showed a mutisensible Escherichia coli. We kept the intravenous antibiotic 2 days longer until the blood test normalized (neutrophilia, CRP levels). Finally, patient was discharged 2 days later with the same oral antibiotic treatment during 2 weeks.

\section{Discussion}

PNE is a life-threatening necrotizing bacterial infection with gas in the excretory system, parenchyma, or perinephric space $[1,2]$. Its incidence is low but it presents a high mortality. Its maximum incidence is around the 5th-6th decade of life, being predominantly in female $(6: 1)$ due to a higher incidence of UTIs in women [2].

Poorly controlled Diabetes Mellitus (DM) is the most frequent (around 100\%) associated risk factor because glucosuria allows the growth of glucose-fermenting bacterias that could leads to infection with gas formation $[3,4]$. Urinary tract obstruction underlies $25-40 \%$ [3]. Other known risk factors are nephrolithiasis, age, previous UTI, alcoholism, inmmunosupresion, end stage renal disease and polycystic kidneys although without statistical significance for increased mortality $[3,5]$. Furthermore, there are poor prognostic factors such as systolic blood pressure $<90$ $\mathrm{mmHg}$, thrombocytopenia, $>50 \%$ renal parenchymal destruction, disturbed level of consciousness, bilaterality or single kidney afected, venous thrombosis and renal failure [3-6].

The most frequent etiologic agent is Escherichia coli (70\%)
$[2,4,7]$. Because as Escherichia coli, Klebsiella pneumoniae, Proteus mirabilis and as Pseudomonas aeruginosa, can ferment glucose to produce gas, predominantly carbondioxide $[7,8]$. About physiopathology factors, hyperglycaemia, renal blood flow decrease and secondary ischemia, immunosuppression or obstructive uropathy may be key factors involved $[4,7]$.

Non-specific symptoms such as fever and abdominal pain are the commonest clinical presentation, nausea, and vomiting with laboratory abnormalities (elevation of acute phase reactants and creatinine levels) are also frequent [4]. The diagnosis is suspected and requires a confirmatory imaging test. Ultrasonography, and mainly $\mathrm{CT}$, detects the presence of gas, being the choice for its greater sensitivity and assessment of the severity [3].

There are multiple classifications to establish the management based on the PNE type [1,3]. The most complete is Huang and Tseng classifications from 2000 based on radiological findings: (I) Gas in excretory system, only; (II) Gas in parenchyma, only; (IIIa) Perinephric extension; (IIIb) Paranephric extension; (IV) PNE in single or bilateral kidney [3]. This classification has a prognosis value and it could be a clinical tool to plannify the optimal treatment according the severity $[4,9,10]$.

The presence of venous thrombosis is a rare presentation of emphysematous pyelonephritis such as occurs in our Case number 1 with renal vein thromobosis in CT findings [5]. It could be possible because sepsis is a prothrombotic state owing to impairment of all antithrombotic pathways $[5,11]$.

Firstly, we should to take into account that some published studies shows that $50 \%$ of patients in Intensive Care Units suffer from disseminated intravascular coagulation complications [12]. So, there is a clear relationship between inflammation, coagulation system and sepsis. Both, inflammation and coagulation works together so thrombi constitute the first-line immune defense in vasculatory system and it is the base of immunothrombosis named by Engelmann et al. [13]. However, systemic thrombosis status because of disseminated intravascular coagulation increases the organ dysfunction and doubles death risk in sepsis $[11,13,14]$.

In this way, it is known that monocytes, macrophages and platelets activate the coagulation system but neutrophil are also involved in these pathways [15].

Platelets recruitment leuckocytes during the sepsis episode, so, they are consumed because of the platelet-leuckocyte complex formation. These conjugates induce proinflammatory events for adhering to the endothelium, generating disturbances in microcirculation. This concept is related to the endotheliopathy $[11,16,17]$ that occurs during the sepsis with the endogenous catecholamines production and the secondary endothelium disruption and endothelial cells injuries.

Anaemiais frequently seen in sepsis patients because of the accelerated apoptosis-like of red cells from circulating blood [11,18]. Erythrocytes are also involved in these immunothrombotic events because they can attract bacterias and fixes them to the erythrocyte's surface to be ingested and killed [19]. Recent studies have reported that erythrocytes suffer from 
eryptosisor erythrocyto's death, when they are infected or nonfunctional and then they keep adhered to endothelium forming clots with immunological functions. But after that, hemoproteins (hem) could have a bactericid role within the immunothrombin or prothrombotic effects if they are free circulating through the blood stream [11,20,21]. Initial management of EPN consists of support measures, fluids (saline, volume expansors), and empirical antibiotic therapy (broad-spectrum antibiotics) [4]. After medical treatment, specific conservative measures, a percutaneous approach and urinary diversion are proposed, preserving the renal unit by $70 \%$ without increasing mortality $[4,9,10]$.

In published meta-analyses, the most successful strategy were support measures associated with the percutaneous approach with lower mortality rates $(13.5 \%)(P<0.0001)$ [2]. Using the Huang and Tseng classification with less than two risk factors, they would benefit from support measures with or without percutaneous diversion, while with more than two risk factors and they require more aggressive measures such as emergency nephrectomy ${ }^{(3)}$. Literature supports that I, II had an excellent

\section{References}

1 Kapoor R, Muruganandham K, Gulia AK, Singla M, Agrawal S, et al. (2010) Predictive factors for mortality and need for nephrectomy in patients with emphysematous pyelonephritis. BJU Int 105: 986-989.

2 LuYC, Chiang BJ, Pong YH, Chen CH, PuYS, et al. (2014) Emphysematous pyelonephritis: clinical characteristics and prognostic factors. Int J Urol 21: 277-282.

3 Huang JJ, Tseng CC (2000) Emphysematous pyelonephritis: Clinicoradiological classification, management, prognosis, and pathogenesis. Arch Intern Med 160: 797-805.

4 Elawdy MM, Osman Y, Abouelkheir RT, El-Halwagy S, Awad B, et al. (2019) Emphysematous pyelonephritis treatment strategies in correlation to the $\mathrm{CT}$ classification: Have the current experience and prognosis changed? Int Urol Nephrol 51: 1709-1713.

5 Jain A, MehraK, Manikandan R, Dorairajan LN (2019) Renal vein and vena caval thrombus: $A$ rare presentation of emphysematous pyelonephritis. BMJ Case Rep 12: e231455.

6 Falagas ME, Alexiou VG, Giannopoulou KP, Siempos II (2007) Risk factors for mortality in patients with emphysematous pyelonephritis: A meta-analysis. J Urol 178: 880-885.

7 Kutwin P, Konecki T, Jabłonowski Z (2014) Emphysematous pyelonephritis in a diabetic patient with obstructed kidney. Cent Eur J Urol 67: 196-198.

8 Dubey IB, Agrawal V, Jain BK (2011)Five patients with emphysematous pyelonephritis. Iran J Kidney Dis 5: 204-206.

9 Saadi A, Ayed H, Bouzouita A, Cherif M, Kerkeni W, et al. (2016) Results of conservative management of emphysematous pyelonephritis. Nephrol Ther 12: 508-515.

10 Eswarappa M, Suryadevara S, John MM, Kumar M, Reddy SB, et al. (2017) Emphysematous pyelonephritis case series from South India. Kidney Int Rep 3: 950-955.

11 Levi M, Schultz M, Van der Poll T (2013) Sepsis and thrombosis. SeminThrombHemost 39: 559-566. prosgnosis even without stent insertion althout catheters are necessary if urinary obstruction exists. On the other hand, nephrectomy is usually needed in III group if there is no response to conservative measures $[3,4,9,10,22,23]$.

In our series, the diabetes rate was $34 \%$. The mortality rate was $34 \%$ and the causative agent was Escherichia coli in $100 \%$ of the cases. The management chosen in each case was urgent nephrectomy in case 1, as it was a dry Type of emphysematous pyelonephritis and a percutaneous approach in the remaining two with good evolution.

\section{Conclusion}

In conclusion, we must know that PNE is an entity that, although infrequent, is a life-threatening disease, usually associated with poorly controlled DM. it requires clinical suspicion and imaging test, preferably $\mathrm{CT}$, to confirm the diagnosis. Initial and early support measures are essential. Nowadays, the most widely accepted treatment is medical management associated with percutaneous diversion. In non-responders or in cases of poor prognosis, urgent nephrectomy may be necessary.

12 Gando S, Iba T, Eguchi Y, Ohtomo Y, Okamoto K, et al. (2006) A multicenter, prospective validation of disseminated intravascular coagulation diagnostic criteria for critically ill patients: Comparing current criteria. Crit Care Med 34: 625-631.

13 Engelmann B, Massberg S (2013) Thrombosis as an intravascular effector of innate immunity. Nat Rev Immunol 13: 34-45.

14 Ogura H, Gando S, Saitoh D, Takeyama N, Kushimoto S, et al. (2014) Epidemiology of severe sepsis in Japanese intensive care units: A prospective multicenter study. J Infect Chemother 20: 157-162.

15 Pfeiler S, Stark K, Massberg S, Engelmann B (2017) Propagation of thrombosis by neutrophils and extracellular nucleosome networks. Haematologica 102: 206-213.

16 Ed Rainger G, Chimen M, Harrison MJ, Yates CM, Harrison P, et al. (2015) The role of platelets in the recruitment of leukocytes during vascular disease. Platelets 26: 507-520.

17 Johansson P, Stensballe J, Ostrowski S (2017) Shock induced endotheliopathy (SHINE) in acute critical illness - A unifying pathophysiologicmechanism. Crit Care 21: 25-31.

18 Kempe DS, Akel A, Lang PA, Hermle T, Biswas R, et al. (2007) Suicidal erythrocyte death in sepsis. J Mol Med 85: 273-281.

19 Minasyan HA (2014) Erythrocyte and leukocyte: Two partners in bacteria killing. Int Rev Immunol 33: 490-497.

20 Lang E, Lang F (2015) Triggers, inhibitors, mechanisms, and significance of eryptosis: The suicidal erythrocyte death. Biomed Res Int 2015: 513-518.

21 Immenschuh S, Vijayan V, Janciauskiene S, Gueler F (2017) Heme as a target for therapeutic interventions. Front Pharmacol 8: 146-160.

22 Sharma PK, Sharma R, Vijay MK, Tiwari P, Goel A, et al. (2013) Emphysematous pyelonephritis: Our experience with conservative management in 14 cases. Urol Ann 5: 157-162.

23 Aboumarzouk OM, Hughes O, Narahari K, Coulthard R, Kynaston H, et al. (2014) Emphysematous pyelonephritis: Time for a management plan with an evidence-based approach. Arab J Urol 12: 106-115. 